\title{
Using TEALE Learning Methodology to Promote Portable Interdisciplinary Accountability in Engineering Education
}

\author{
http://dx.doi.org/10.3991/ijep.v3iS3.2751 \\ Lynroy Grant ${ }^{1}$, Akram Abu-aisheh $^{1}$, and Alan Hadad ${ }^{1}$, Barbara Poole ${ }^{2}$ \\ ${ }^{1}$ University of Hartford, West Harford, CT, USA \\ ${ }^{2}$ Roger Williams University, Bristol, RI, USA
}

\begin{abstract}
Research suggests that an increase in learner mobility across formal and informal jurisdictions is a positive response to an integrated global economy and workforce. To facilitate ebbs and flows of maintaining a mobile global workforce, the literature suggests that engineering education should promote methodology and learning mechanisms that personalize accountability of learners' content knowledge across jurisdictions. In addition, data from the literature suggests that the cyber-learning mechanism for supporting mobility generates massive amounts of data which when refined could inform engineering educators in their response to an increasingly mobile workforce. This paper reviews data from a pilot study of a TechnologyEnhanced Autonomous Learning Environment (TEALE). TEALE is a framework for mobile learning environments that afford accountability of personalized evidence-based content across learning jurisdictions.
\end{abstract}

Prelimary data from this third pilot report suggests that TEALE promotes accountability of content knowledge across learning jurisdictions: both among formal disciplines in the academy, as well as between the academy, informal learning and workplace requirements. However, the data also suggests that seamless mobility across these academic and social jurisdictions involves issues far beyond technology. These issues, which include adjudicating relevance and value among academic cultures, incentives for motivation, authority and autonomy should be accounted for when using TEALE. Attention to these issues could prevent engineering educators from viewing potential opportunities for inter-jurisdictional collaborations as encroachments and avert the specter of unintended social-dramas.

Index Terms-learning algorithms; Informal learning; formal learning; Leaner Agent; Portfolio; LAO; Technology-Enhanced; Autonomous Learning; TEALE.

\section{INTRODUCTION}

According to Sellen and Harper [11], affordances are defined as activities that an integrated environment allows, enables, or affords. Based on this definition, affordances of our global digital interdependent environment are beginning to have huge implications for engineering education.

There is a broad consensus in the literature that affordances of technology are transforming engineering education [1-2]. There are also indications that this transformation is displacing traditional boundaries among disciplines in the academy, and between formal and informal learning in general [1]. Expectations resulting from displacement of both traditional physical barriers and socio-cultural boundaries are increased mobility and interdisciplinary collaborations. It appears that a new social arrangement for teaching and learning is emerging that anticipates more transparency and inter-disciplinary accountability to accommodate this increased mobility and inter-disciplinary collaborations [5].

However, while there is an expressed desire for collaboration in response to this transformation, there is no coherent consensus in the literature on a framework for adjudicating inter-disciplinary collaborations that accommodate mobility between formal and informal learning or for leveraging affordances of the technologies that are rapidly changing the engineering education environment [2, $3 \& 12]$. The urgency for a systemic framework for collaboration is underscored by The National Academy of Engineers [39], The American Society for Engineering Education (ASEE) [40], and The Royal Academy of Engineering [1]. Reports from these organizations suggest that none of the world's current major engineering challenges will be solved without collaboration from other disciplines.

For example, ASEE-2012 document "Innovation with Impact: Creating a Culture for Scholarly and Systematic Innovation" highlighted the urgency for more collaboration across disciplines and between formal and informal learning.

In fact a common theme throughout the ASEE-2012 document is that solutions to "...technical and nontechnical challenges in engineering education are now inseparable..." in an emerging integrated global environment $[1,11]$. An extension of this theme is that affordances of an integrated environment driven by more open social engagement will be the key to solutions of future challenges.

Massive Open Online Courses (MOOC) is one example of this affordance. MOOCs are delivered by our leading engineering institutions over the web to thousands of students at a time, with options for synchronous or asynchronous learning controlled by students' (learner) convenience and interests [5].

The potential impact of MOOCs on engineering education highlights the need for a coherent systemic teaching and learning arrangement which assumes a more mobile and autonomous learner. Indications are MOOCs and other digital affordances are just a first step in what an emerging environment of ubiquitous information technol- 
ogy affords. One example from this affordance is an expectation of seamless movement of autonomous learners between formal learning, informal learning, and the workplace [5].

According to the literature, affordances from a digital environment of mobile autonomous learners have engendered many successes in engineering education but also have created many technical and non-technical challenges and opportunities. Indications are that jurisdictions of formal learning, informal learning and the workplace have different, and often competing, interests. At the moment, there is no common engineering education interdisciplinary arrangement, or set of tools, for adjudicating seamless movement of autonomous learners between these jurisdictions. There are suggestions that any successful arrangement or set of tools will be part of a systemic structural transformation, more far reaching than "a mishmash of traditional lecturing with some online content" [6].

Research on creating a common framework for engaging autonomous learners in engineering education is limited. This gap in the literature is particularly evident for movements of autonomous learners between formal and informal academic jurisdictions. The search for more seamless collaborations is not new or unique to engineering education. According to Pieters and Baumgartner in their understanding of "who talks to whom," in both intraand inter-disciplinary communication, no area of economics appears to build substantially on insights from its sister disciplines [16].

There are many research efforts that capitalize on new technological advances toward improving seamless interdisciplinary collaborations. One example, from among many, is to explore alternative teaching and learning environments and ecosystems in which the National Science Foundation (NSF) and the journal Science created the International Science and Engineering Visualization competition as a way of promoting alternative forms of communicating science, engineering, and technology for education and journalistic purposes, [2223 . Another example is the collaboration of many institutions to explore potential opportunities of Open Courseware.

However, for many reasons beyond the scope of this paper, these collaborations have been generally reactive or piecemeal, and have not resulted in major systemic change to facilitate a seamless movement of individuals between the "K-16" engineering education infrastructure, and informal learning, workforce requirements and beyond to lifelong learning as informed citizens $[1,5]$.

This study explores social-cultural issues of autonomous learning, which is defined as learning anchored to a portable, technology enhanced, and independent environment customized to enable multiple means of representation, expression, and engagement toward allowing individuals to pursue what is most important in their lives [8]. This definition combines elements from the National Center on Universal Design for Learning (UDL) [12], research in foreign languages [14 \& 15], and from other areas $[1,7]$.

The purpose of this ongoing pilot study is to explore a proof of concept that demonstrates how to capitalize on available technology for creating a more comprehensive and seamless framework that affords on-going real-time movements between formal and non-formal learning, and also between classroom experiences and the workplace. Understanding and articulating sociocultural issues engendered by digital affordances across the academy is a broader but secondary goal of the paper. The ongoing limited pilot study is being conducted at University of Hartford's College of Engineering, Technology, and Architecture (CETA) and Roger Williams University's Gabelli School of Business.

Data from this third preliminary report indicates that a coherent systemic framework for portable interdisciplinary accountability in engineering education can be constructed from Technology-Enhanced Autonomous Learning Environments (TEALE). Indications are that TEALE increased time-on-task, emotional investment, improved independence, autonomous learning, and continuous professional identity development.

TEALE is a portable individualized learning environment with capability of evidence-based interdisciplinary accountability across learning jurisdictions. Research on TEALE is an ongoing pilot study at the University of Hartford using data from selected technical mathematics and electronics communication courses. TEALE has three major conceptual components: (1) the Learner Agent Objects (LAO) which are individual academic portfolio elements in a collection of evidence-based multimedia proxies and artifacts representing a learner's formal and informal academic experience; (2) the meta-data system that provides automated learning assistance by employing algorithms from learning sciences to influence, anticipate, evaluate, and manage individual learning activities; and (3) the communication interface that interacts with other TEALEs, remote labs, and external learning resource libraries.

The study continues to raise important questions about the future of digital affordances in engineering education that require more conversations and research. This limited work only highlights the possibility that TEALE and LAO could be useful tools for accommodating transparent collaboration between the different, or competing, interests in the engineering education enterprise as technology continues to enable unprecedented changes in our lives.

\section{ENGINEERING EDUCATION AND AFFORDANCES OF A DIGITAL ENVIRONMENT}

As in the two earlier preliminary report reports, elements used in explaining affordances of paper can be applied to engineering education. As indicated previously, affordances are activities an object allows, or affords. In the case of a digital environment of ubiquitous information technology, affordance is what the technology allows. However, for engineering education institutions to benefit from the full extent of what technology allows they "...cannot comfortably evolve ...but instead must muster the courage to leave behind the old and redefine..." new teaching and learning processes for the world we are facing $[6$, p. 628, 11]. The challenge is that some of the old models for teaching engineers are currently productive, economically sound, and even thriving. All sound management decisions would suggest staying the course. To make matters more complicated, the quality of new teaching and learning processes is generally viewed as a lower standard and appeals to a "different" population. One example is the issue of quality with online engineering education. 
However, Christensen, Horn and Johnson [36] argue that these counter-intuitive - and what may be seen as reckless - business decisions, to "disrupt class" are actually example of "How Disruptive Innovation Will Change the Way the World Learns." They believe that not making these counter-intuitive decisions about how to use affordances of emerging technologies is the reason why once successful organizations fail. The flaw in these decisions, they argue, is the focus on how these affordances could maintain and grow their organization using the current population (or increase the current population), while ignoring the potential benefits of these affordances for serving in different ways or serving totally different populations. They believe academic institutions are at risk of making the same mistake of following conventional wisdom. The following are some issues that support their case in terms of affordances from seamless movements of autonomous learners between formal learning, informal learning, and the workplace.

The academy is more urgently in search of a common process that engages movements across different, often competing, jurisdictions. There is a clear consensus in the literature that with emerging technologies, the future of engineering education involves more interdisciplinary communication and collaboration [27]. But there is silence about whose academic cultural norms, practices, and ways of knowing will be used in such collaboration. In the global economy for example, because the technology affords (allows) it, English has evolved as a common process for conducting international commerce, while respecting local languages and customs. It may prove difficult to ask engineering educators to adopt the cultural language of knowing and doing of other disciplines and vice versa.

Looking at the full spectrum of possibilities of what seamless movement of autonomous learners affords, there may be a way for the academy to accommodate communication and collaboration across interdisciplinary cultures and ways of knowing in the "language" of their discipline, while providing effective relevance to the autonomous learner. One approach is to use affordances of technology to make students (learners) full partners of the academy. As Christensen, Horn and Johnson indicated these new partners of the academy may be viewed as "lesser quality" but adding this "different" population may be the key to the academy's future success. In this approach, the academy would be academically engaged with groups of autonomous learners, accountable for supporting each other for life instead of just a few years of undergraduate and graduate school engagement. This arrangement would be akin to an academic and career "marriage" of sorts, and would resolve some interrelated issues of sustainability which go beyond affordances of technology.

\section{AUTONOMOUS AND INDEPENDENT LEARNING}

There are more than technology issues to seamless movement of autonomous learners. A review of the literature reveals that emerging technologies are credited with displacing traditional boundaries between types of learning, and for removing physical barriers to seamless movements between formal and informal learning communities. However, potential benefits and side effects from affordances of seamless movements between formal and informal learning communities in a digital environment raise interrelated questions that go far beyond technology issues. For example: issues of economics, of incentives for motivation, of authority and autonomy, of entitlement to validate and marshal authenticity, of philosophy of education, and of "legitimate" ways of knowing, are among the array of elements continuously influencing each other.

As mentioned earlier, one evolving issue that goes far beyond technology is the legitimizing of Open Course Ware (OCW) online engineering courses by top brand name universities, which is forcing other universities to react swiftly to how engineering education will be delivered in the future. For example, among MOOCs started just in 2012 are Coursera which boasts of offering courses from over thirty universities, including Stanford University, University of Virginia, Duke University, University of Pennsylvania and University of Illinois, and exX offered by Harvard, MIT, Berkeley, and others.

Indications are any systemic solution for seamless engineering education teaching and learning environments must account for these evolving issues of digital affordances. For this research, one conceptual solution for communication and collaboration across the academy is for autonomous learners to use the TEALE framework. For this study, autonomous learning is defined as learning anchored to a portable, enhanced, and independent environment customized to enable multiple means of representation, expression and engagement toward allowing individuals to pursue what is most important in their lives [p. 239, 41].

\section{Ongoing Pilot Study}

This is an ongoing pilot study for over five years in search of articulating useful processes and best practices for educating engineers for the $21^{\text {st }}$ century [23-25]. The researchers, from different colleges and disciplines, began with the latest information about how people learn [22, $35]$, reviewed progress and accomplishments [28, 30], and the emerging meaning of engineering education, and how to leverage affordances of technology. A first report of preliminary data was "Fostering Learner Mobility between Engineering Education and a Twenty First Century Workplace" [12]. A second report of preliminary data was "Successful Integration of Informal Learning in Engineering Education" [3]. Both of these reports demonstrated proof of the concept of general constructs for learner mobility, and established points of reference for future work.

This paper represents a third report of preliminary data, which builds on previous literature review and research data. The focus this time was articulating and demonstrating proof of concept, that a coherent systemic framework for portable interdisciplinary accountability, and continuous professional identity development in engineering education can be constructed from Autonomous Learning Environments (TEALE).

Toward that end, three major working assumptions have been used: (1) Affordances of a digital environment bring different meanings to the teaching and learning process. (2) Cumulative artifacts, simulations, and metadata can represent and influence an individual's learning experiences both in and out of the formal engineering education setting. (3) When learners control artifacts that represent their cumulative content knowledge they will invest more emotional interest in maintaining these 
artifacts. By-products are: improved time on task, independent learning, and content revisions or continuous professional identity development, which is shown to be correlated with how people learn [22].

\section{TECHNOLOGY ENHANCED AUTONOMOUS LEARNING ENVIRONMENTS (TEALE) FRAMEWORK}

This report revised the conceptual learning methodology model to make distensions between the Technology Enhanced Autonomous Learning Environment (TEALE) and its functional sub-systems Learner Agent Objects (LAO) that directly engage the learner. For example, a word processing package could be viewed as an LOA, because it acts as an agent in direct response to the learner's needs and ambitions in communicating with his or her environment. Likewise, Drop-Box or Google Drive could be viewed as a TEALE that contains LAOs. This distension allows for mixing and matching appropriate ubiquitous or off-the-shelf technology for individual learners. However, because ubiquitous technologies sometimes offer both functionalities of TEALE and LAO, for this paper TEALE include both learning environment (TEALE) and learning agent objects (LAO) unless otherwise stated.

TEALE and LAO are not specific technologies or even confined to a specific pedagogical methodology; rather, TEALE is a framework of ideas for creating and transferring knowledge in a digital enhanced environment where the capability of the student (learner) transcends his or her "...biological limitations" [31]. LAO and TEALE aim to use the affordance of digital technology to extend our perception of the individual's capabilities to communicate, to control those aspects of their lives that they view as important, and make decisions as an informed citizen. This affordance includes continuously accumulating academic artifacts, and simulations, in a permanent personal library for supporting the individual's interaction with stakeholders in the teaching and learning process. Support capabilities are grouped in at least three categories:

1. Artifacts, simulations, and meta-data that represent and influence an individual's learning experiences both in and out of formal engineering education;

2. Exchanging ideas with others;

3. Analyzing and solving problems. One assumption is that over time and as digital technology matures, the usefulness of this personal library or hub of knowledge would render it an extension of the individual much as a limb or organ in the teaching and learning process.

TEALE is grounded in a long history of successful, but piecemeal efforts, among the disciplines in STEM education. These piecemeal efforts include, but are not limited to: First Year Interest Groups (FIG); intelligent learning systems; object-orientated education technology and related interconnectivity applications; project based learning and active learning methods; increased application of market principles in education; philosophy and ethics for digital education enterprises; and heightened interest in understanding how people learn [22]. Students (learners) are generally the only consistently common element but with the least control in these efforts. The focus of TEALE is to allow learners to present more complete information about their academic situation to stakeholders in STEM and engineering education.

The TEALE framework draws heavily from a category of FIGs, implemented at the University of Hartford and other locations, which by design uses existing infrastructures (both physical and epistemological) to support small curricular units called Integrated Learning Blocks (ILB). However, in the wake of a critical cohort of maturing technologies reaching a practical tipping point, tools from instructional technology, computer and cognitive sciences are employed to expand the ILB concept into smart continuous learning agents. In this project, TEALEs expand the one-year FIG model to include pre-college experience and the entire college years, and continue with life beyond college. Developing a TEALE infrastructure provides a valuable academic hub and scaffolding for supporting life-long learning and also the potential for creating new revenue streams for higher education.

TEALE raises important philosophical issues about its usefulness in creating the knowledge and ethics about digitally enhanced knowledge of students (learners) in a digital environment. For example, there are questions of control, self-interest, the nature of digital property, and compatibility. However, knowledge associated with this academic experience and other important philosophical concerns are not the focus of this paper.

In addition, issues of LAO as a smart agent of the individual in a digital environment are also not the focus of this paper, and are best pursued elsewhere using existing agency theory research as a starting point. This is only a beginning attempt of a first step toward constructing a framework of ideas in search of solutions about how to perceive enhanced learning, and enhanced learners, in three broad areas.

1. To prepare future technologists,

2. To prepare future engineers, and

3. To provide a timely delivery system for educating the country's workforce. To demonstrate the proof-ofconcept of TEALE, and LAO in these three categories, Blackboard, Google Docs, Drop-Box SkyDrive, among others, were used as a digital container where students continuously accumulate their best work from selected classes.

\section{DATA AND Methodology}

Blackboard is the University of Hartford's primary course management system. It is augmented by Drop Box, Google Drive, and Microsoft Sky-Drive, as TEALE (knowledge proxy containers) and LAO to simulate a seamless environment for ubiquitous information technology. For the purpose, of this study references to Blackboard mean combined knowledge containers and learner agent objects. The study used these knowledge containers or individual academic portfolios, to organize artifacts of students' accumulative academic work. Frequency of access to these documents was used as an indicator of student interest, and content of data files were reviewed to measure level of student collaboration and content knowledge.

The content of the student work posted on Blackboard forms a library of reusable objects (fixed) for subsequent exams, assignments, self-assessment and future classes. For example, from Course Statistics on Blackboard, researchers were able to determine that students, and 
alumni, are using their content files years after a course was completed.

An ethnographic exploratory study was started in 2006 to test the concept of LAO. Students from classes taught by selected faculty members (technical mathematics and electrical engineering) were asked initially to post their "best work" in three-ring binders used in formats required by the Accreditation Board for Engineering and Technology (ABET). However after one semester, three-ring binders were replaced with posting students" "best work" on Blackboard where it could be observed by other students, faculty and staff. As of September 2012, the number of participants in the study is 200. Participants taking multiple courses were counted once.

Rubrics for class assignments and tests were created for the TEALE framework for each class. In general, tests and class assignments were returned to the students with a conditional grade. Grades are never marked in these documents. However, grades are not official until students make the necessary corrections to their work and post the edited content (best work) on Blackboard (grades are not included). Because of the limitations of Blackboard, a separate Blackboard class was created with one discussion board for all students to share their work from multiple semesters. Each student would create one thread with his or her names, and then reply to his or her names attaching a file with his or her best work (Microsoft Word, text, graphics, videos, or PDF files). Each file on average contains material covered by a major topic or chapter of the textbook. For example, one file may contain three completed problems from each section of a textbook chapter, with full explanations of each step.

High level of expertise is expected from the student who presents his or her best work. That is, the focus is not on the source of the content, or what help the student received compiling the content but instead the focus is placed on how well the student can explain and apply the content that is presented. For this study, students are expected to be tested at any time, and in different forms, about the material they post on Blackboard. This expectation of mastery, or ownership, of posted material is not just confined to faculty, or students in the class, but to others involved in the academic life of the student.

Training is provided on how to use textbooks and other resources. Specifically, training involves learning to read the examples in the text first before doing the exercises. Training also involves learning how to maintain, and apply content to other related areas. For example, it helps the student combine different class contents and content from other disciplines into a continuous and meaningful whole.

Faculty members are encouraged to use the posting on Blackboard as one way of understanding the academic history of their students, as well as using the posted material as a way of linking to what students already know. Not only works of students are posted in the area, but also sample solutions by faculty and other reference material are posted.

Initially, the number of one-on-one student teacher conferences relating to these activities increased by more than $70 \%$ with conference time averaging 25 minutes. Since the initial semester, student conferences have been decreasing by an average of $4.8 \%$ each semester, with the average time of conferences decreasing by $6 \%$ each semester. In September 2012 the average conference time was 8 minutes. A conference management system was used to track details of the conferences (purpose of conference, start time, stop time, comments, location, number of students etc.).

\section{PREMILINARY RESUlTS}

Using primitive or static LAO artifacts (Microsoft Word, PDF and Text files) to represent best work of students Ethnograph application version 6.0 generated significant student to student, and faculty-to-student activities in relation to what the literature considered seven best practices in teaching [32-34]:

1. Increasing faculty-student interaction. Facultystudent interaction tends to be shorter but more frequent. Major reasons for the interactions include acting as referee for competing ideas in class projects, as consultant in solving a mathematics problem, and as a negotiator with students working for a better grade.

2. Fostering collaboration among students and providing prompt feedback. Students perceive having casual conversation about technical mathematics problem with their peers as exotic enough to merit curious inquiry. Patterns of understanding course content sometimes display a "viral" effect similar to YouTube or Wikipedia, and are more effective in communicating some technical ideas than traditional approaches.

3. Encouraging active learning and emphasizing time on task. Posting best work encourages more active participation in class work, increases attention to detail, increased emotional investment, and adds more relevance to technical mathematics.

4. Communicating high expectations while addressing different learning styles. The idea of posting class assignments after they are graded and edited allows students with different learning styles to produce the same high quality products.

Before the end of the first semester student activities quickly took on a combined YouTube and Wikipedia effect where posting best work from class assignments, special projects, and related materials became a symbol of personal and professional pride, a focus of social drama, and academic collaborations across subject areas and some university programs.

Some examples of social dramas include:

1. Students would challenge other's ability to do the work they posted. As such posting class content brought social status, but also the responsibility of justifying one's knowledge of the subject.

2. Communication about what was covered in previous classes improved, given that samples of the material were accessible and available to all interested parties in the teaching and learning process.

3. Time on task improved as measured by the Blackboard statistics. Students used the area all hours of the day with the period of time of 12 hours before classes recording the highest usage.

Samples of collaboration include the following: 
1. Instances of students working with each other have increased. From observation, conversation about posting work, or questions about work posted and other out of class activities started occurring only after students start posting their work on Blackboard and realize they were actually writing questions for their own examination.

2. Student-student interaction about class content increased significantly, and some questions that were directed at faculty were directed to other students leaving space for different questions and issues for the faculty to handle. In addition, with their work posted on Blackboard, students found it easier to find alternative pedagogical resources other than the teacher.

3. Maintaining an atmosphere of individualized on demand instruction required extra time and resources. The same energy that motivated students to collaborate could quickly become distracting if faculty or qualified resources were not available to adjudicate conflicts, lack of information, appropriate scaffolding resources or other related issues.

4. Having libraries of students' best work also improved early warning collaboration among faculty and staff. For example, students who were having problems, for one reason or another, generally have significantly less work to show.

TEALE is a work in progress, and more work is needed to document the full benefits and side effects, smart learner agents (LAO) and TEALE bring to a digitized academic environment. Preliminary data from CETA student demonstrates TEALE's proof of concept in six general areas:

1. Reducing piecemeal fragmentations in engineering education toward a systemic and seamless whole,

2. Creating echo systems of sharable best practices

3. Providing framework for adjudicating accountability, value, and costs analysis in engineering education.

4. Creating potential new higher education revenue streams from continuous subscription based learning and

5. Enabling interdisciplinary stakeholders of the learner to collaborate in their native academic ways of knowing and doing in the education process.

\section{SUMMARY AND CONCLUSIONS}

This study introduced the concept of TEALE as a digital container for artifacts and simulations of CETA students' (learners) academic experiences as only the beginning step in a long process of research, conversations and negotiations towards a fundamental understanding of designing learning environments relevant to the needs of future engineers. The concept of autonomous learning was introduced to describe users of TEALE and LAO who bring self-interest to a broader range of technology affordances for engineering education.

The series of emerging themes from this exploratory study show proof of concept that TEALE and LAO have the potential for improving STEM education in five general areas:

1. Collaboration between selected technical mathematics and electrical engineering education toward a seamless whole;
2. Echo systems of sharable best practices (including ethics or collaboration in a digital education environment);

3. Pedagogical relationships in the teaching and learning process;

4. Potential for creating new higher education revenue streams through long-term academic relationships;

5. Interdisciplinary stakeholders of the learner to collaborate in their native academic ways of knowing and doing in the education process;

6. Promoting continuous professional identity development.

The study also indicates that the TEALE's framework has implications on different levels in the teaching and learning process [25-28]. At the classroom level, students are encouraged to use appropriate (native) technology for communicating their understanding of content. At the institutional and community levels the TEALE framework provides building blocks for multidisciplinary collaboration while affirming native academic dialects and ways of knowing, diverse interests, and multiple levels of participants. This shared system of best work evolves throughout the learner's academic life-cycle and creates a practical way for integrating lifelong SETM learning into our current higher education system.

\section{REFERENCES}

[1] The Royal Academy of Engineering. (2012). Achieving excellence in engineering education: The ingredients of successful change. London: The Royal Academy of Engineering.

[2] Graham, Ruth (2012). The One Less Traveled By: "The Road to Lasting Systemic Change in Engineering Education." Journal of Engineering Education: 101(4), pp. 596-600 http://dx.doi.org/10.1002/j.2168-9830.2012.tb01120.x

[3] Ahmad Abu-aisheh, Akram and Grant, Lynroy (2012), "Successful Integration of Informal Learning in Engineering Education," International Journal of Advanced Corporate Learning (iJAC), Vol 5, No 2 pp. 4-9.

[4] Engel, Renata and Giddens, Don (2011). "From Our Reading List to Yours: A Summary of Key Reports." Journal of Engineering Education: 100(2), pp. 220-224 http://dx.doi.org/10.1002/j.21689830.2011.tb00011.x

[5] EDUCAUSE (2012). "What Campus Leaders Need to Know About MOOCs." EDUCAUSE is a nonprofit association whose mission is to advance higher education through the use of information technology. Retrieved 2 December 2012, from http://net.educause.edu/ir/library/pdf/PUB4005.pdf

[6] Peercy, Paul, and Cramer, Steven. (2011). "Redefining Quality in Engineering Through Hybred Instruction." . Journal of Engineering Education: 100(4), pp. $625-629$. http://dx.doi.org/10.1002/j.2168-9830.2011.tb00029.x

[7] Bell, Philip, Bruce Lewenstein, Andrew W. Shouse, and Michael A. Feder, Editors (2009). Learning Science in Informal Environments: People, Places, and Pursuits. Washington, DC: The National Academies Press.

[8] Fenichel, Marilyn and Heidi A. Schweingruber; National Research Council. Surrounded by Science: Learning Science in Informal Environments. Washington, DC: The National Academies Press, 2010.

[9] Shouse, A.W. Lewenstein, B. Feder, M.A., \& Bell, P (2010). "Crafting Museum Experiences in Light of Research on Learning: Implications of the National Research Council's Report on Informal Science Education." Curator, 53(2), pp. 137-153. http://dx.doi.org/10.1111/j.2151-6952.2010.00015.x

[10] [10]Mote, C. D (2011). "Strategic issues facing public public universities. Paper presented at The American Association for the Advancement of Science (AAAS) Annual Meeting, Washington, DC. 
[11] Sellen, Abigail \& Harper, Richard. (2003). "The Myth of the Paperless office". MIT. Boston, MA.

[12] Ahmad Abu-aisheh, Akram \& Grant, Lynroy (2011), "Fostering Learner Mobility between Engineering Education and a Twenty First Century Workplace," International Journal of Advanced Corporate Learning (iJAC), Vol 4, No 2 pp. 4-8.

[13] National Center on Universal Design for Learning (UDL) (2011). UDL At A Glance. Retrived from http://www.udlcenter.org/about udl/whatisudl/conceptofudl

[14] Holec, H., 1981: Autonomy and foreign language learning. Oxford: Pergamon. (First published 1979, Strasbourg: Council of Europe)

[15] Little, David. (2010). "Learner autonomy and second/foreign language learning." Centre for Languages, Linguistics and Area Studies. Retrieved 7 October 2011, from http://www.llas.ac.uk/ resources/gpg/1409

[16] Pieters, Rik, and Baumgartner, Hans. (2002). "Who Talks to Whom? Intra- and Interdisciplinary Communication of Economics Journals". Journal of Economic Literature: 40(2), pp. 483-509. http://dx.doi.org/10.1257/002205102320161348

[17] Alabanese M., \& Mitchell, S. "Problem-based learning: a review of literature on its outcomes and implementation issues," Academic Medicine, Vol. 68, 1993, No. 1.

[18] Baker, D. A., \& Witt, P. A. (1995). Evaluation of the impact of two after-school programs. Journal of Park and Recreation Administration, 14(3), 60-81.

[19] Huang, R. X., M. A. Cane, N. Naik, and P. Goodman (2000), Global adjustment of the thermocline in response to deepwater formation, Geophys. Res. Lett., 27(6), 759-762 http://dx.doi.org/ 10.1029/1999GL002365

[20] Wang, M. C., Haertel, G. D., \& Walberg, H. J. (1993). Toward a knowledge base for school learning. Review of Educational Research, 63(3), 249-294. http://dx.doi.org/10.3102/0034654306 $\underline{3003249}$

[21] Learning Processes Task Group. (2007). National Mathematics Advisory Panel Progress Report. United States Department of Education.

[22] Donovan, Suzanne, John D. Bransford, and James W. Pellegrino, (Eds.). How people learn: bridging research and practice. Committee on Learning Research and Educational Practice, Commission on Behavioral and Social Sciences and Education, National Research Council.

[23] [23] National Research Council, Rising above the gathering storm: Energizing and employing America for a brighter economic future, Washington, DC: National Academies Press, 2005.

[24] [24] National Academy of Engineering, The engineer of 2020, Washington, DC: National Academies Press. 2004.

[25] National Academy of Engineering, Educating the engineer of 2020: Adapting engineering education to the new century, Washington, DC: National Academies Press, 2005.

[26] [26] Watson, K. "Change in Engineering Education: Where Does Research Fit? Journal of Engineering Education 98 (1): 3-4., $2009,3$.

[27] Sheppard, S. D., W. J. Pellegrino, M. B. Olds, "On Becoming a 21 st Century Engineer", Journal of Engineering Education 97 (3): 231-38, 2008, 231
[28] Huang, D. (2001). An after-school evaluation system for middle and high school programs. NAASP Bulletin, 45(626), 45-61. http://dx.doi.org/10.1177/019263650108562605

[29] Pieters, R., and Baumgartner, H. "Who Talks to Whom? Intraand Interdisciplinary Communication of Economics Journals." Journal of Economic Literature: 40(2), pp. 483-509, 2002, 2.

[30] Center for the Advancement of Scholarship on Engineering Education (CASEE). (2005-2006). "Progress and Accomplishments: Engineering Education Research and Development": Washington, DC: National Academy of Engineering.

[31] Kurzweil, Ray. (2005) The Singularity is near: when humans transcend biology. Penguin Group. New York, New York.

[32] Chickering, Arthur and Stephen C. Ehrmann (1996), "Implementing the Seven Principles: Technology as Lever," AAHE Bulletin, October, pp. 3-6.

[33] Chickering, A.W., \& Gamson, Z.F. (1987). Seven principles for good practices in undergraduate education. "American Association of Higher Education Bulletin", 3-7.Gibson, J. J. (1986). "The Ecological Approach to Visual Perception". Lawrence Erlbaum Associates, Inc. Hillside, New Jersey.

[34] Alabanese M., "Problem-Based Learning: why curricular are likely to show little effect on knowledge and clinical skills," Medical education, Vol. 34, No.9, 2000, P.729. http://dx.doi.org/10.1046/j.1365-2923.2000.00753.x

[35] Bransford, J., A. Brown, and R. Cocking. How people learn: Brain, mind, experience, and school. Washington, DC: National Academy Press, 1999.

[36] Christensen, Clayton, Michael Horn, and Curtis Johnson. (2008). Disrupting Class: How Disruptive Innovation Will Change the way the world Learns. McGraw-Hill: New York, NY.

[37] Gabriele, G. 2005. Advancing engineering education in a flattened world. Journal of engineering Education: 94(2):3-5.

[38] Gibson, J. (1986). "The Ecological Approach to Visual Perception”. Lawrence Erlbaum Associates, Inc. Hillside, New Jersey

[39] The National Academy of Engineers (2011) "Engineer of 2020 project.

[40] The American Society for Engineering Education-ASEE (2012) "Innovation with Impact: Creating a Culture for Scholarly and Systematic Innovation."

[41] Moss, Frank (2011). The Sorcerers and Their Apprentices: How the Digital Magicians of the MIT Media Lab Are Creating the Innovative Technologies That Will Transform Our Lives. Random House, Inc.

\section{AUTHORS}

Lynroy Grant, Akram Abu-aisheh, and Alan Hadad are with College of Engineering, Technology, and Architecture (CETA), University of Hartford, West Harford, CT-06117, USA, lygratnt@hartford.edu.

Barbara Poole is with Gabelli School of Business, Roger Williams University, Bristol, RI 02809, USA.

This article is an extended and modified version of a paper presented at the EDUCON2013 conference held at Technische Universität Berlin, Berlin, Germany from March 13-15, 2013. Received 12 May 2013. Published as resubmitted by the authors 21 May 2013. 